\title{
Variabilidade genética em búfalos estimada por marcadores RAPD
}

\author{
Maria do Socorro Maués Albuquerque (1), Andréa Alves do Egito(1), José Ribamar Felipe Marques(1), \\ Ana Yamaguishi Ciampi(1), Arthur da Silva Mariante ${ }^{(1)}$, Sílvia Tereza Ribeiro Castro(1), Maria Rosa Costa(2), \\ Samuel Rezende Paiva ${ }^{(1)}$, Aline Marinho da Silva ${ }^{(3)}$ e Eucleia Primo Betioli Contel ${ }^{(4)}$
}

\begin{abstract}
(1)Embrapa Recursos Genéticos e Biotecnologia, PqEB, Final Av. W5 Norte, s/no, Caixa Postal 02372, CEP $70770-900$ Brasília, DF. E-mail: maues@cenargen.embrapa.br, egito@cenargen.embrapa.br, aciampi@cenargen.embrapa.br, mariante@cenargen.embrapa.br, silvia@cenargen.embrapa.br, samuel@cenargen.embrapa.br, (2)Embrapa Amazônia Oriental, Trav. Dr. Enéas Pinheiro, s/noo, Caixa Postal 48, CEP 66095-100 Belém, PA. E-mail: marques@cpatu.embrapa.br, mrco@embrapa.br (3)Universidade de Brasília, Campus Universitário Darcy Ribeiro, Caixa Postal 04508, CEP 70910-970 Brasília, DF. E-mail: alinecmarinho@yahoo.com (4)Universidade de São Paulo, Fac. de Medicina de Ribeirão Preto, Dep. de Genética, Av. Bandeirantes, no 3.900, CEP 14049-900 Ribeirão Preto, SP. E-mail: epbconte@rge.fmrp.usp.br
\end{abstract}

\begin{abstract}
Resumo - O objetivo deste trabalho foi caracterizar, por meio de marcadores RAPD, dois grupos genéticos de búfalos, Carabao e tipo Baio, que estão sendo conservados in situ, assim como verificar as relações genéticas entre eles e os outros três grupos genéticos de búfalos existentes no Brasil, Murrah, Jafarabadi e Mediterrâneo, considerados raças comerciais. Foram estudados 48 animais de cada grupo, com exceção dos grupos Murrah e Mediterrâneo, com 47 e 42 animais, respectivamente, compreendendo um total de 233 animais. Os 21 iniciadores polimórficos geraram 98 marcadores. A variabilidade genética entre e dentro dos grupos foi estimada em 26,5 e 73,5\%, respectivamente, sugerindo divergência significativa entre os cinco grupos genéticos. Na análise entre pares de grupos, foi verificado que a maior e a menor divergência estavam em torno de 40 e $18 \%$, quando se compararam os grupos Carabao x Mediterrâneo e Murrah x Jafarabadi, respectivamente. Entre os grupos Baio e Murrah, a análise revelou divergência genética de 20,42\%, indicando que esses grupos são distintos. Os cinco grupos são geneticamente distintos, o que reforça a necessidade de conservação dos grupos genéticos Carabao e Baio, ameaçados de extinção no Brasil.
\end{abstract}

Termos para indexação: Bubalus bubalis, caracterização genética, marcadores moleculares.

\section{Genetic variability of buffaloes estimated by RAPD markers}

\begin{abstract}
The objective of this work was to characterize genetically, using RAPD markers, two genetic groups of buffalos, Carabao and Baio, which are being conserved in situ, as well as to verify the genetic relationship among them and the other three genetic groups of buffalos raised in Brazil, considered as commercial breeds: Murrah, Jaffarabadi and Mediterrâneo. Forty eight animals of each group were studied, with the exception of the Murrah and Mediterrâneo, in which 47 and 42 animals, respectively, were sampled, comprising a total of 233 animals. The 21 polymorphic primers produced 98 markers. Genetic variability within and between groups was estimated in 26.5 and $73.5 \%$, respectively, suggesting a significant divergence among groups. On the analysis between pairs of groups, the divergence was about 40 and 18\%, respectively, when the Carabao x Mediterranâneo and the Murrah x Jaffarabadi were compared. The estimated genetic divergence between Baio and Murrah groups was $20.42 \%$, indicating that they are distinct groups. The five genetic groups are genetically distinct, indicating the need to conserve the Carabao and Baio, two genetic groups in danger of extinction in Brazil.
\end{abstract}

Index terms: Bubalus bubalis, genetic characterization, molecular markers.

\section{Introdução}

A espécie bubalina foi introduzida no Brasil em 1890, quando animais da raça Mediterrâneo chegaram na Ilha de Marajó. Nos anos seguintes, outras importações foram realizadas, resultando na difusão dos búfalos pelas diversas regiões brasileiras, sendo a região Norte a que concentra maior número de animais dessa espécie. As quatro raças reconhecidas oficialmente pela Associação Brasileira de Criadores de Búfalos (ABCB) são Murrah, Jafarabadi, Mediterrâneo e Carabao, sendo as três primeiras denominadas búfalos de rio, e a última 
pertencente ao grupo de búfalos de pântano. O tipo Baio, um grupamento genético com pequeno número de animais, e o Carabao encontram-se ameaçados de extinção no Brasil (Marques et al., 2003).

No Brasil, as características produtivas e reprodutivas dos bubalinos vêm sendo estudadas por diversos autores, entre eles Cassiano et al. (2003) e Tonhati et al. (2004). No entanto, ainda são raros os trabalhos com marcadores bioquímicos e moleculares na espécie bubalina. Del Lama \& Zago (1996), utilizando marcadores bioquímicos para comparar bubalinos do grupo Murrah com zebuínos das raças Gir e Nelore, por meio dos locos k-caseína e da $\beta$-lactoglobulina, observaram variação genética nas raças bovinas, não tendo encontrado polimorfismos na espécie bubalina. Iorio et al. (2004) estudaram parâmetros de diversidade genética em duas populações de búfalos de regiões distintas do Sul da Itália, utilizando marcadores bioquímicos e moleculares e não verificaram diferenças genéticas significativas entre elas.

A sobrevivência de uma espécie depende de sua variabilidade genética, e a quantificação dessa variabilidade pode ser um parâmetro predominante na caracterização de raças de animais. A análise do DNA possibilita detectar a existência de marcadores genéticos polimórficos, que podem ser usados em estudos evolutivos, mapeamento genético, identificação de paternidade, taxonomia molecular, introgressão de genes, diagnóstico genético precoce e seleção assistida por marcadores (Nicholas, 1999). Por meio das técnicas moleculares, foi possível avançar no conhecimento das características de um indivíduo, quanto ao genótipo, a partir de amostras de sangue, pêlos e tecidos. A técnica de RAPD (Random Amplified Polymorphic DNA) foi desenvolvida por Williams et al. (1990), e pode ser utilizada para quantificar a variabilidade genética entre e dentro de diferentes grupamentos genéticos, em espécies distintas.

No Brasil, foram usados marcadores RAPD para caracterizar populações eqüinas (Fuck, 2002) e raças bovinas (Spritze et al., 2003; Rangel et al., 2004; Serrano et al., 2004), e para diferenciar subpopulações caprinas (Oliveira, 2003). Utilizando a mesma metodologia, Paiva (2001) avaliou efeitos de obstáculos naturais na estruturação de populações em espécies de peixes. Gimenez et al. (2003) analisaram subespécies de suínos e seus híbridos, e Oliveira et al. (2004) determinaram as distâncias genéticas entre populações de abelhas de 25 localidades, de três países da América Latina.
A técnica de RAPD também foi utilizada por Appa Rao et al. (1996), para estudar a distância genética entre três espécies da família Bovidae (Bos indicus, Ovis aries e Capra hircus) e Bubalus bubalis, na tentativa de detectar marcadores genéticos espécie-específicos. Saifi et al. (2004) utilizaram marcadores RAPD para verificar a identidade genética entre as raças Murrah e Bhadawari.

Este trabalho teve como objetivo estimar a variabilidade genética entre e dentro dos cinco grupos de bubalinos criados no Brasil, a similaridade genética entre eles e a variabilidade genética dentro dos núcleos in situ de bubalinos Carabao e tipo Baio.

\section{Material e Métodos}

Foram utilizados neste trabalho 233 bubalinos dos grupos genéticos Murrah $(\mathrm{N}=47)$, Jafarabadi $(\mathrm{N}=48)$, Carabao ( $\mathrm{N}=48)$, Baio $(\mathrm{N}=48)$ e Mediterrâneo $(\mathrm{N}=42)$, amostrados em 11 rebanhos dos Estados do Pará, Goiás, Distrito Federal e São Paulo (Tabela 1). Foram selecionados, preferencialmente, animais livres de parentesco, formando, assim, uma amostra representativa, seguindo o proposto por Barker (1994).

O DNA genômico foi extraído a partir dos linfócitos, seguindo a metodologia de Miller et al. (1988). Dos 145 oligonucleotídeos iniciadores randômicos testados, 21 apresentaram um número maior de marcadores polimórficos, que foram utilizados para amplificação de todos os indivíduos.

Cada reação de amplificação apresentou volume final de $13 \mu \mathrm{L}$, contendo: 10 ng de DNA genômico;

Tabela 1. Número de búfalos analisados em cada grupo genético, por Fazenda/Estado.

\begin{tabular}{llc}
\hline Grupo genético & \multicolumn{1}{c}{ Fazenda/Estado } & Número de animais \\
\hline Baio & Bagam $^{(1)}$, PA & 48 \\
Carabao & Bagam, PA & 48 \\
Mediterrâneo & Felisberto Camargo, PA & 23 \\
& Santo Anjo, SP & 19 \\
Murrah & Felisberto Camargo, PA & 8 \\
& Upis ${ }^{(2)}$, DF & 23 \\
& Babaçu, DF & 9 \\
& Agropecuária Monte Alto, DF & 7 \\
Jafarabadi & Itaqui, PA & 19 \\
& Cachoeirinha, GO & 14 \\
& Boa Vista, SP & 15 \\
\hline Total & & 233 \\
\hline
\end{tabular}

(1)Banco de Germoplasma Animal da Amazônia. (2)União Pioneira de Integração Social (Upis), Faculdades Integradas de Brasília. 
0,4 $\mu \mathrm{M}$ de oligonucleotídeos iniciadores arbitrários; 20 mM Tris-HCl (pH 8,4); 50 mM KCl; 2,5 mM MgCl ; $200 \mu \mathrm{M}$ de cada dNTP; $8 \%$ de BSA a 2,5 $\mathrm{mg} \mathrm{mL}^{-1}$; e 1,5 U de Taq DNA polimerase. As reações de amplificação foram dirigidas pelos iniciadores OPA08, OPA12, OPA15, OPA16, OPA17, OPA19, OPA20, OPB01, OPB11, OPE12, OPJ06, OPJ12, OPJ17, OPK9, OPK10, OPK16, OPN20, OPAE01, OPAE09, OPAE10 e OPJ14, na seguinte programação: (1) desnaturação inicial da fita dupla a $94^{\circ} \mathrm{C}$ por 5 minutos; (2) desnaturação a $94^{\circ} \mathrm{C}$ por 1 minuto; (3) anelamento dos iniciadores a $36^{\circ} \mathrm{C}$ por 1 minuto; (4) extensão a $72^{\circ} \mathrm{C}$ por 2 minutos; e (5) extensão final a $72^{\circ} \mathrm{C}$ por 5 minutos. Os passos 2,3 e 4 constituíam um ciclo, que foi repetido por 40 vezes. Os produtos amplificados foram separados por eletroforese em gel de agarose a 1,4\%, utilizando tampão de corrida TBE (Tris-borato EDTA). Os géis foram corados com brometo de etídeo. O padrão de peso molecular de $1 \mathrm{~kb}$ (DNA Ladder de 1.000 bases) foi utilizado em cada gel, permitindo estimar o tamanho dos fragmentos amplificados. Os fragmentos foram visualizados na forma de bandas, depois da exposição à luz ultravioleta, e documentados em aparelho de fotodocumentação Eagle Eye.

Os marcadores foram analisados de acordo com a presença (1) ou ausência (0) de uma dada banda e organizados em forma de matriz binária. Nas análises genéticas populacionais e estatísticas intra e inter-raciais, foram utilizados os programas TFPGA (Tools For Population Genetics Analysis) (Miller, 1997) e AMOVA (Excoffier et al., 1992). A análise de componentes principais utilizou o coeficiente de similaridade de Dice (Dice, 1945) e as matrizes correlacionadas. O agrupamento é visualizado em relação a três eixos de coordenadas de componentes principais, CP1, CP2 e CP3, do NTSYS-PC (Numerical Taxonomy and Multivariate Analysis System), versão 2.1 (Adams et al., 2002).

\section{Resultados e Discussão}

Dos 145 iniciadores testados, 76 (52,41\%) apresentaram amplificações de fragmentos polimórficos, $28(19,31 \%)$ foram monomórficos, ao passo que $41(28,28 \%)$ apresentaram fragmentos fracos, com pouca consistência, ou não apresentaram fragmentos. Estes resultados foram inferiores aos encontrados por Gimenez et al. (2003), em estudos com javalis e suínos domésticos, quando observaram polimorfismos em $70,10 \%$ dos iniciadores testados.
Dos 76 iniciadores que apresentaram amplificações, foram escolhidos 21, que atendiam às exigências de possuir pelo menos três bandas polimórficas e padrão de amplificação desejável (Figura 1).

Noventa e oito marcadores RAPD foram gerados pelos 21 iniciadores selecionados, com 344 a 2.036 pb. O número de bandas polimórficas geradas variou de 3 a 11 por oligonucleotídeo iniciador, com média de 4,6 bandas. Utilizando RAPD na caracterização de bovinos, Spritze et al. (2003) e Serrano et al. (2004) obtiveram média de 5,5 bandas por iniciador, enquanto Gimenez et al. (2003) obtiveram média de 10,7 bandas por iniciador, ao analisar diferentes criações de javalis no Estado de São Paulo. Considerando que esse número pode variar de acordo com a população estudada, os resultados encontrados estão dentro do esperado. Os iniciadores OPB11 e OPE12 geraram maior polimorfismo, com 9 e 11 bandas, respectivamente. A confiabilidade dos ensaios RAPD pode ser verificada no experimento para amplificação de todos os indivíduos do grupo Jafarabadi (Figura 2).

A quantificação da variabilidade genética entre e dentro dos cinco grupos genéticos, verificada pela análise de variância molecular (AMOVA), foi estimada em 26,5 e 73,5\%, respectivamente, sugerindo divergência genética significativa (Tabela 2). Serrano et al. (2004), analisando bovinos de raças naturalizadas, obtiveram valores semelhantes (29,96 e 70,04\%), evidenciando que a maior parte da variância genética ocorreu em virtude de diferenças entre indivíduos dentro das populações. Esses resultados estão de acordo com Iorio et al. (2004),

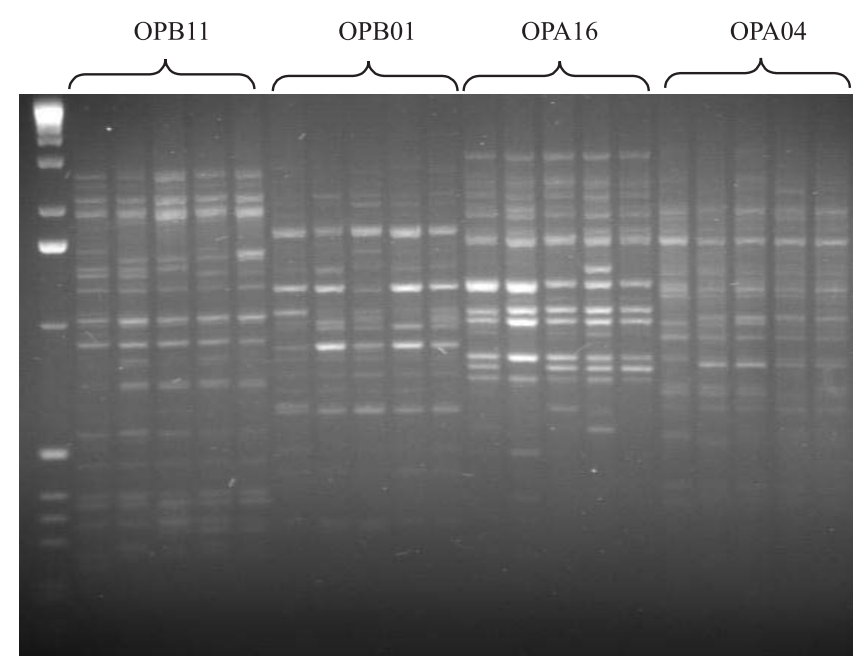

Figura 1. Triagem de oligonucleotídeos iniciadores mostrando diferentes padrões de amplificação. 


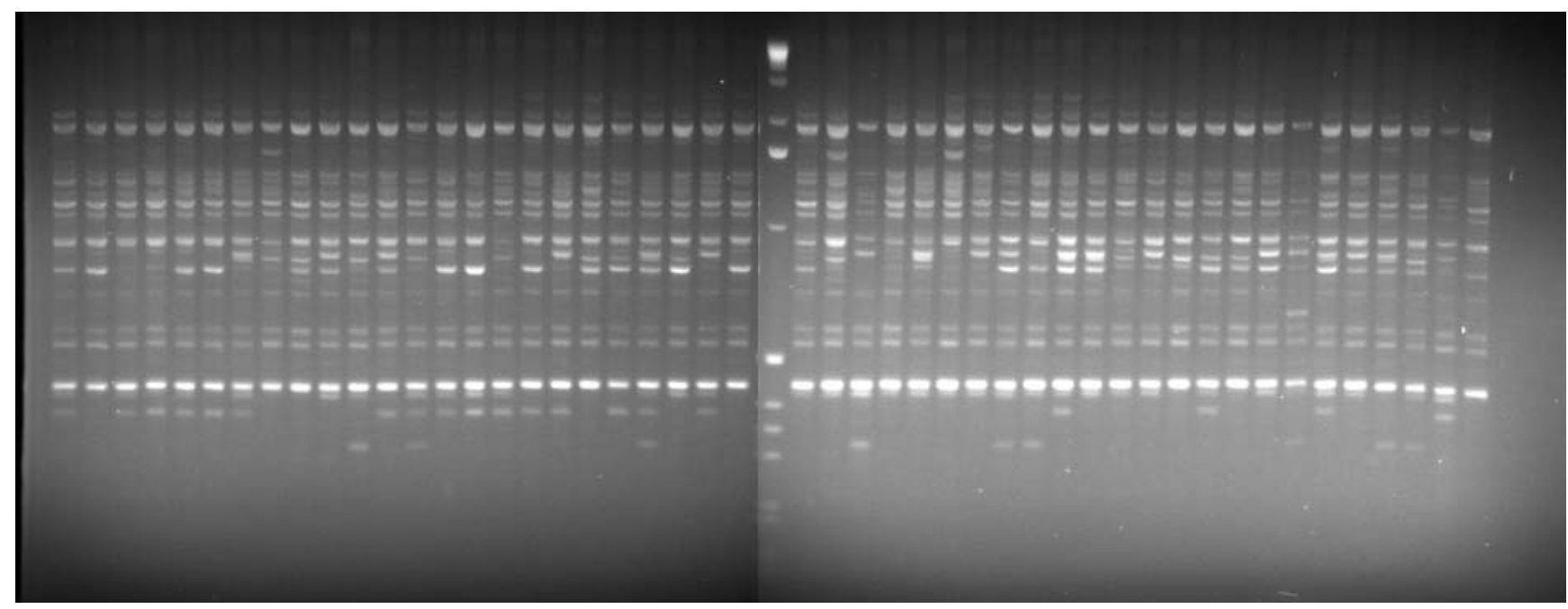

Figura 2. Amplificação dos indivíduos estudados no grupo Jafarabadi, com o iniciador OPA08.

Tabela 2. Análise de variância molecular entre os cinco grupos genéticos de búfalos: Baio, Carabao, Mediterrâneo, Murrah e Jafarabadi ${ }^{(1)}$.

\begin{tabular}{lcccc}
\hline Fonte de variação & GL & $\begin{array}{c}\text { Soma dos } \\
\text { quadrados }\end{array}$ & $\begin{array}{c}\text { Componentes } \\
\text { de variância }\end{array}$ & $\begin{array}{c}\text { Porcentagem } \\
\text { de variação }\end{array}$ \\
\hline Entre populações & 4 & $1.008,279$ & 5,06644 & 26,50 \\
Dentro de populações & 228 & $3.232,614$ & 14,05484 & 73,50 \\
\hline Total & 232 & $4.240,890$ & 19,13129 & \\
\hline
\end{tabular}

(1)Todos os valores apresentaram diferenças estatísticas significativas $(\mathrm{p}<0,0001)$.

que observaram diferenças maiores dentro das populações, quando analisaram a diferenciação genética em duas populações de búfalos utilizando polimorfismos protéicos.

O agrupamento por similaridade pode ser verificado na análise dos componentes principais, nos quais a correlação das variâncias foi projetada nos eixos CP1, CP2 e CP3. Entre eles, o CP1 apresentou maior variância (69,48\%), evidenciando cinco grupamentos genéticos bem definidos, com poucas exceções (Murrah e Baio) e uma nítida separação entre os grupos Mediterrâneo e Carabao (Figura 3). Esse mesmo resultado foi verificado na AMOVA, que mostrou divergência em torno de $40 \%$, quando os grupos genéticos foram analisados aos pares (Tabela 3). Este resultado, altamente significativo $(\mathrm{p}<0,0001)$, pode estar sendo influenciado pela inclusão, no grupo Mediterrâneo, de animais especializados, descendentes de touros italianos, que fazem parte do programa de melhoramento genético da Fazenda Santo Anjo, SP. Os índices de divergência, também elevados, obtidos quando o grupo Mediterrâneo foi comparado aos grupos Baio (30,9\%), Murrah (24,6\%) e Jafarabadi (29,9\%) também podem corroborar esta

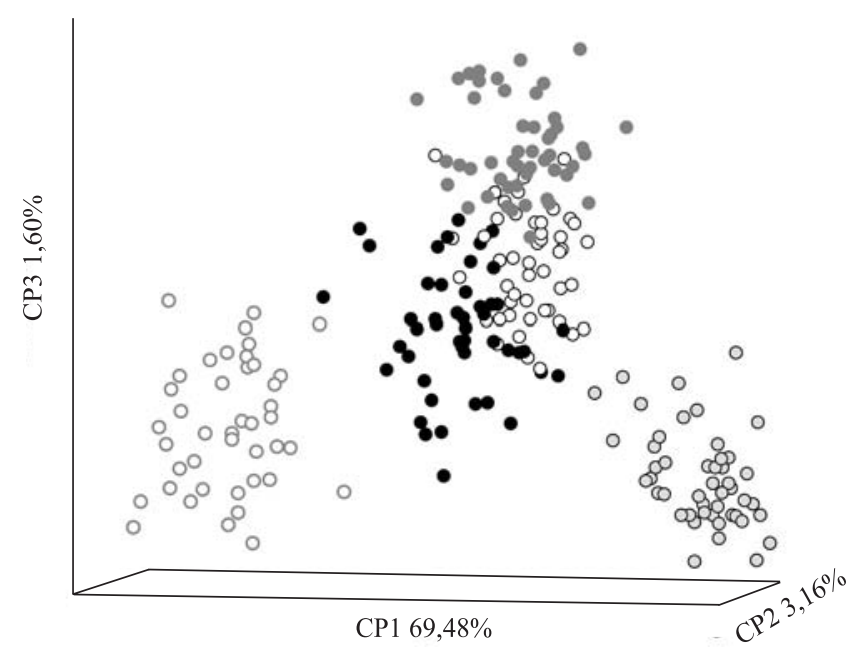

Figura 3. Análise de componentes principais obtida a partir do coeficiente de Dice de 233 búfalos pertencentes a cinco grupos genéticos do Brasil: Mediterrâneo ○, Carabao O, Jafarabadi @, Murrah @ Baio o. Os eixos CP1, CP2 e CP3 evidenciam a correlação entre as variáveis padronizadas mostrando os grupamentos em três dimensões.

hipótese. A menor divergência, obtida na comparação com Murrah, pode ser explicada pela possível introdução de genes da raça Mediterrâneo, para aumentar a base genética do rebanho Murrah no Brasil (Marques et al., 2003).

Na mesma análise, os demais grupos, confrontados aos pares, mostraram 20,42\% de divergência entre os grupos Baio e Murrah (Tabela 3). A partir deste resul- 
tado, pode-se afirmar que são grupos genéticos distintos, contrariando a hipótese do tipo Baio pertencer ao grupo Murrah (Marques et al., 2000).

A menor divergência ocorreu em torno de 18\%, quando foram analisados os grupos Murrah e Jafarabadi. Este índice pode refletir o fato de os dois grupamentos genéticos terem sido submetidos, no passado, a cruzamentos alternados entre si, sem, no entanto, alterar de maneira significativa o pool gênico original dos grupos, os quais podem ser considerados geneticamente distintos, embora haja grupos gênicos compartilhados.

Quando foram confrontados os grupos em conservação Baio e Carabao, a análise apontou divergência genética de 26,5\%, mostrando que o manejo reprodutivo ao qual esses grupos vêm sendo submetidos, no núcleo de conservação, está sendo adequado. Embora todos os resultados sinalizem para uma alta divergência entre os grupos estudados, observaram-se índices elevados, quando cada um dos grupos foi confrontado com o grupo Carabao, fato que pode ser explicado por este grupo pertencer à subespécie Bubalus bubalis kerebau e não Bubalus bubalis bubalis, como os demais.

As análises mostraram valores para porcentagem de locos polimórficos variando entre 79,59 e 92,86\%, nos grupos genéticos Baio e Jafarabadi, respectivamente. Tais resultados podem estar relacionados com o fato de o grupo Jafarabadi ter sofrido, no passado, cruzamentos com as demais raças. Quanto ao Baio, o resultado pode ser explicado por tratar-se de uma população que vem sendo mantida há vários anos no Banco de Germoplasma, sem ter havido introdução de animais de outro rebanho. A alta porcentagem de locos polimórficos indica que os iniciadores RAPD utilizados podem ser indicados para outras análises de variabilidade genética, em búfalos.

Tabela 3. Porcentagem da variabilidade genética entre os pares de grupos genéticos, estimada pela análise de variância molecular ${ }^{(1)}$.

\begin{tabular}{lcccc}
\hline Grupos genéticos & Baio & Carabao & Mediterrâneo & Murrah \\
\hline Baio & - & - & - & - \\
Carabao & 26,55 & - & - & - \\
Mediterrâneo & 30,95 & 40,19 & - & - \\
Murrah & 20,42 & 26,01 & 24,60 & - \\
Jafarabadi & 19,80 & 27,36 & 29,95 & 18,43 \\
\hline
\end{tabular}

(1)Todos os valores apresentaram diferenças estatísticas significativas $(\mathrm{p}<0,0001)$.

\section{Conclusões}

1. Os marcadores moleculares RAPD apresentam potencial informativo para a quantificação da variabilidade genética e diferenciação dos grupos de búfalos existentes no Brasil.

2. Os cinco grupos estudados podem ser considerados populações geneticamente distintas, reforçando a necessidade de conservação dos grupos genéticos Carabao e Baio.

3. O grupo Mediterrâneo é o mais divergente, quando comparado aos grupos Jafarabadi, Baio e Carabao.

\section{Agradecimentos}

À Upis e aos proprietários das Fazendas Agropecuária Monte Alto, Babaçu, Santo Anjo, Itaqui, Cachoeirinha, Boa Vista e Felisberto Camargo, que cederam material biológico (sangue); à Sudam, pelo fornecimento de parte dos recursos financeiros.

\section{Referências}

ADAMS, D.; KIM, J.; JENSEN, R.; MARCUS, L.; SLICE, D.E.; WALKER, J. NTSYSpc: numerical taxonomy and multivariate analysis system, version 2.10z. [S.l.]: Applied Biostatistics, 2002. Não paginado.

APPA RAO, K.B.C.; BHAT, K.V.; TOTEY, S.M. Detection of species-specific genetic markers in farm animals through random amplified polymorphic DNA (RAPD). Genetic Analysis: Biomolecular Engineering, v.13. p.135-138, 1996.

BARKER, J.S.F. A global protocol for determining genetic distances among domestic livestock breeds. In: WORLD CONGRESS ON GENETICS APPLIED TO LIVESTOCK PRODUCTION, 5., 1994, Guelph, Canada. Proceedings. Guelph: International Committee for World Congresses on Genetics Applied to Livestock Production, 1994. v.5, p.501-508.

CASSIANO, L.A.P.; MARIANTE, A. da S.; McMANUS, C.; MARQUES, J.R.F.; COSTA, N.A. da. Caracterização fenotípica de raças bubalinas nacionais e do tipo Baio. Pesquisa Agropecuária Brasileira, v.38, p.1337-1342, 2003.

DEL LAMA, S.N.; ZAGO, M.A. Identification of the k-casein and $\beta$-lactoglobulin genotypes in Brazilian Bos indicus and Bubalus bubalis populations. Brazilian Journal of Genetics, v.19, p.7377, 1996.

DICE, L.R. Measures of the amount of ecologic association between species. Ecology, v.26, p.297-302, 1945.

EXCOFFIER, L.; SMOUSE, P.E.; QUATTRO, J.M. Analysis of molecular variance inferred from metric distances among DNA haplotypes: application to human mitochondrial DNA restriction data. Genetics, v.131, p.479-491, 1992.

FUCK, B. Uso de marcadores moleculares RAPD na caracterização genética molecular das raças bovinas nativas 
brasileiras. 2002. 58p. Dissertação (Mestrado) - Universidade de Brasília, Brasília.

GIMENEZ, D.L.; MOTA, L.S.L.S. da; CURI, R.A.; ROSA, G.J. de M.; GIMENES, M.A.; LOPES, C.R.; LUCCA, E.J. de. Análise cromossômica e molecular do javali europeu Sus scrofa scrofa e do suíno doméstico Sus scrofa domesticus. Brazilian Journal of Veterinary Research and Animal Science, v.40, p.146-154, 2003.

IORIO, M.; VINCENTI, D.; ANNUNZIATA, M.; RULLO, R.; BONAMASSA, R.; DI LUCCIA, A.; PIERAGOSTINI, E. Biochemical and molecular investigations on qualitative and quantitative $\mathrm{Hb}$ polymorphism in the river buffalo (Bubalus bubalis L.) population reared in Southern Italy. Genetic and Molecular Biology, v.27, p.167-173, 2004.

MARQUES, J.R.F.; COSTA, M.R.; EGITO, A.A.; MARIANTE, A. da S.; ALBUQUERQUE, M.S.M. Conservation of genetic resources of the small populations of domestic animal of the Amazon Region in Brazil. Animal Genetic Resources Information, v.33, p.31-40, 2003.

MARQUES, J.R.F.; DIAS, A.V.S.; TEIXEIRA, J.C.; CASSIANO, L.A.P. Origem, domesticação e classificação zoológica. In: MARQUES, J.R.F. (Ed.). Búfalos: o produtor pergunta, a Embrapa responde. Brasília: Embrapa Comunicação para Transferência de Tecnologia, 2000. 176p. (Embrapa Comunicação para Transferência de Tecnologia. Coleção 500 perguntas, 500 respostas).

MILLER, M.P. TFPGA: tools for population genetics analyses: a Windows Program for the analysis of allozyme and molecular population genetic data. [Logan: Utah State University], 1997. Disponível em: <http://www.marksgeneticsoftware.net/>. Acesso em: set. 2005.

MILLER, S.A.; DYKES, D.D.; POLESKY, H.F. A simple salting out procedure for extracting DNA from human nucleated cells. Nucleic Acids Research, v.16, p.1215, 1988.

NICHOLAS, F.W. Introdução à genética veterinária. Porto Alegre: Artmed, 1999. 328p.

OLIVEIRA, R. de C.; NUNES, F. de M.F.; CAMPOS, A.P.S.; VASCONCELOS, S.M. de; ROUBIK, D.; GOULART, L.R.; KERR,
W.E. Genetic divergence in Tetragonisca angustula Latreille, 1811 (Hymenoptera, Meliponinae, Trigonini) based on RAPD markers. Genetics and Molecular Biology, v.27, p.181-186, 2004.

OLIVEIRA, R.R. Caracterização genética de populações de caprinos da raça Moxotó usando marcadores moleculares. 2003. 58p. Dissertação (Mestrado) - Universidade Federal da Paraíba, Areia.

PAIVA, S.R. Influência de obstáculos naturais na divergência de populações de Astyanax bimaculatus na Bacia do Rio DoceMG. 2001. 55p. Dissertação (Mestrado) - Universidade Federal de Viçosa, Viçosa.

RANGEL, P.N.; ZUCCHI, M.I.; FERREIRA, M.E. Similaridade genética entre raças bovinas brasileiras. Pesquisa Agropecuária Brasileira, v.39, p.97-100, 2004.

SAIFI, H.W.; BHUSHAN, B.; KUMAR, S.; KUMAR, P.; PATRA, B.N.; SHARMA, A. Genetic identity between Bhadawari and Murrah breeds of Indian buffaloes (Bubalus bubalis) using RAPDPCR. Asian-Australasian Journal of Animal Sciences, v.17, p.603-607, 2004.

SERRANO, G.M.; EGITO, A.A. do; McMANUS, C.; MARIANTE, A. da S. Genetic diversity and population structure of Brazilian native bovine breeds. Pesquisa Agropecuária Brasileira, v.39, p.543-549, 2004.

SPRITZE, A.; EGITO, A.A. do; MARIANTE, A. da S.; McMANUS, C. Caracterização genética da raça bovina Crioulo Lageano por marcadores moleculares RAPD. Pesquisa Agropecuária Brasileira, v.38, p.1157-1164, 2003.

TONHATI, H.; MUÑOZ, M.F.C.; DUARTE, J.M.C.; REICHERT, R.H.; OLIVEIRA, J.A.; LIMA, A.L.F. Estimates of correction factors for lactation length and genetic parameters for milk yield in buffaloes. Arquivo Brasileiro de Medicina Veterinária e Zootecnia, v.56, p.251-257, 2004.

WILLIAMS, J.G.; KUBELIK, A.R.; LIVAK, K.J.; RAFALSKI, J.A.; TINGEY, S.V. DNA polymorphisms amplified by arbitrary primers are useful as genetic markers. Nucleic Acids Research, v.18, p.65316535, 1990.

Recebido em 6 de dezembro de 2004 e aprovado em 14 de setembro de 2005 